\title{
Enhanced model for ergonomic evaluation of information systems: application to scientific research information system
}

\author{
Khaoula Benmoussa $^{1}$, Majida Laaziri ${ }^{2}$, Samira Khoulji ${ }^{3}$, Mohamed Larbi Kerkeb ${ }^{4}$, Abir El Yamami \\ ${ }^{1,2,3}$ Information System Engineering Resarch Group, National School of Applied Sciences, \\ Abdelmalek Essaadi University, Morocco \\ ${ }^{4}$ Information System Engineering Resarch Group, Faculty of Sciences, Abdelmalek Essaadi University, Morocco \\ ${ }^{5}$ Laboratory Signals, Distributed Systems and Artificial Intelligence, ENSET Mohammedia,
} Hassan II University, Morocco

\section{Article Info \\ Article history: \\ Received Feb 10, 2018 \\ Revised Aug 9, 2018 \\ Accepted Aug 24, 2018}

\section{Keyword:}

Ergonomic evaluation

Heuristic inspection

Human-machine Interaction

Information system

SIMArech

\begin{abstract}
Considering the importance of the ergonomic aspect for information systems in providing an easy use of the computing systems, this paper focuses on the elaboration of a hybrid model for the ergonomic evaluation of information systems that merges a set of inspection dimensions such as accessibility, practicality, emotionality, and technological persuasion. Details on how the model has been constructed and data have been collected are presented. For the evaluation of our model, a situation of an information system for scientific research (SIMArech) in Moroccan Universities has been studied. This model can be used by ergonomist and human factor professionals. It is found that the proposed heuristics can effectively assess the most important dimensions of scientific research information systems.
\end{abstract}

Copyright (C) 2019 Institute of Advanced Engineering and Science. All rights reserved.

\section{Corresponding Author:}

Benmoussa Khaoula,

Information System Engineering Resarch Group,

National School of Applied Sciences, Abdelmalek Essaâdi University,

Mhannech II, B.P 2121 Tetuan, Morocco.

Email: benmoussakhaoula24@gmail.com

\section{INTRODUCTION}

Today, numerous studies in Human-Computer Interaction (HMI) have revealed new ergonomic criteria and ergonomic grids and recommendations. Critical analysis of computer systems goes through the concepts of ergonomics, heuristic inspection has long been considered part of the evaluation phase or the design process of the computer system. This assessment is based ergonomic criteria represent the major ergonomic dimensions according to which an interface can be evaluated or specified, and several researches have been conducted on the comprehensibility and evolution of these evaluation criteria.

In this context, the authors [1], [2] have highlighted Web Accessibility Assessment and Guidelines, the author [3] emphasized the evaluation of usability, the authors [4] have emphasized the importance of the place of emotions in interaction with machines, the authors [5] developed and validated an ergonomic grid to guide the inspection of persuasive interfaces. Yet, there is to date no formal model for the ergonomic assessment of information system that combines all the inspection dimensions.

this contribution proposes a new model that combines a set of 31 criteria for the ergonomic assessment of information systems partitioned in 4 main dimensions (i.e. accessibility, practicality, emotionality and persuasivity) which makes it possible to deduce strengths and improvement points. In order to evaluate ourmodel [6], the ergonomic quality of Moroccan information system of scientific research (SIMArech) [7] has been studied. 
The rest of this paper is organized as follow: firstly, a literature review about the subject is presented in section 2. Section 3 presents user-centered evaluation methods. Section 4 introduces the ergonomic evaluation proposed model, then a case study has been performed in section 5. Finally, the results are analysed and discussed in Section 6 before concluding.

\section{LITERATURE REVIEW}

Ergonomic assessment of interactive systems is an important and essential step in the user-centered design cycle [8]. Psychological studies conducted on humans have shown certain abilities as well as a certain number of limits. The purpose of ergonomics is to take advantage of these psychological elements in order to implement an efficient and comfortable interface to use. According to the author [9] has defined ergonomics as "scientific knowledge of the man at work, under the various physiological, sociological and medical aspects of human work." This scientific knowledge, aims to a practical objective which conditions and justifies the very existence of ergonomics: the adaptation of work to man. Ergonomics therefore has a vast field of investigation that takes into account the constraints of physical and mental work during humanmachine interactions.

Ergonomics has a tradition of producing standards, recommendations and criteria. The ergonomics of HMIs has often been illustrated by inspection methods, some of which are well known and often used. The purpose of the ergonomic evaluation is to verify that the interactive system meets a set of recommendations and ergonomic rules [10]. Let us quote the classification of criteria of the authors [11], which makes it possible "to formalize and to structure the ergonomic knowledge, in particular as it appears in the form of recommendations" [12] .These Ergonomic Criteria thus represent "the major ergonomic dimensions according to which an interactive system may be evaluated or specified".

\section{USER CENTERED EVALUATION METHODS}

Choosing a user-centric, method of use on the use of information systems (seen as interactive systems) is not an easy task. In this regard, several approaches have been proposed for the classification of methods for evaluating interactive systems: the author [13] distinguishes evaluation methods according to behavioral data (empirical methods) or data on the interface ( analytical methods); the author [14] classifies the methods according to several criteria possibly decomposed into subcriteria (knowledge required, material resources, situational factors, human resources, results provided by the evaluation), the author [15] separates the approaches of evaluation according to three central elements of the human-machine interaction, which are the user, the task and the system. the authors [16] propose two main categories: the methods requiring the direct participation of the users and those applying to the characteristics of the interface. the authors [17] based on [18], classify the evaluation methods according to the presence actual or represented user and system;

It should be noted that the most used methods are listed by ISO / TR 16982: 2002 [19]. They are most often focused on the utility and usability criteria of the author [20] [21]. In this paper, we use the classification of authors [18], which classifies evaluation methods into 3 main approaches as shown in Figure 1:

a. Approaches focused on the opinions and / or activities of users,

b. Qualified expert approaches focused on the judgment of experts in human-machine communication or the use of evaluation grids or questionnaires listing the qualities of a good HMI,

c. The approaches described as analytical, centered on a modeling of the human-machine interaction.

These most often consist of performing the evaluation using objective metrics based on a descriptive model of human tasks, or from a description of the screen pages. However, as the authors point out [15], [18], [9], it would seem unrealistic to consider these groupings independently. Indeed, cross-relationships between methods are often very useful. 


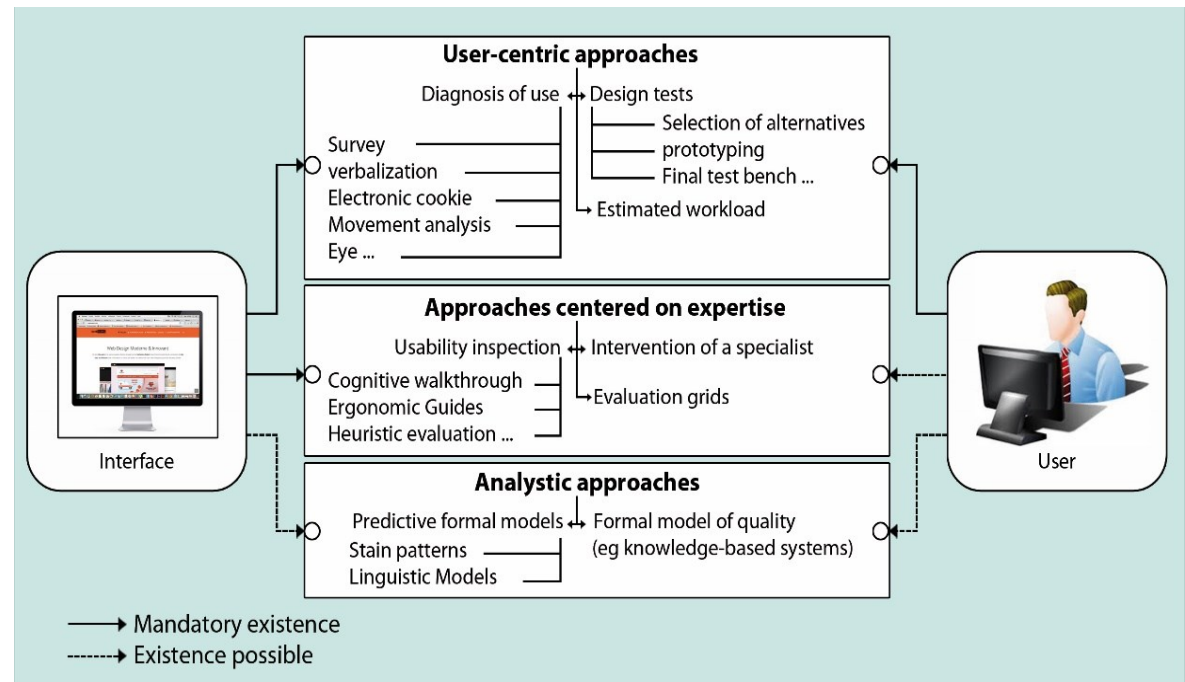

Figure 1. Excerpt from the classification of adaptive assessment methods and techniques [22], [23]

\section{PROPOSED MODEL}

We present trough Table 1, the proposed hybrid model that combines accessibility, usability, Emotionality and Persuasivity criterias. Each dimension will be described below.

Table 1. Ergonomy Evaluation Proposed Model

\begin{tabular}{|c|c|c|}
\hline & Criteria & Subcriteria \\
\hline \multirow[t]{22}{*}{ Accessibility } & 1.1.Perceptibility & 1.1.1. Equivalence of contents. \\
\hline & & 1.1.2. Sensoriality of contents. \\
\hline & & 1.1.3.Assistance with the presentation of invisible formats etc. \\
\hline & 1.2.Comprehensibility & 1.2.1. Readability. \\
\hline & & 1.2.2. Predictability of messages. \\
\hline & & 1.2.3. Consistency of navigation. \\
\hline & & 1.2.4. Assistance with the seizure. \\
\hline & & 1.2.5. Understanding of errors Error recovery procedure etc. \\
\hline & 1.3.Robustness & 1.3.1. Compatibility. \\
\hline & & 1.3.2. Conformity. \\
\hline & & 1.3.3. Easy to modify system controls. \\
\hline & & 1.3.4. Controllable by the user. \\
\hline & 1.4.Usability & 1.4.1. Perception of deadlines and feedbacks. \\
\hline & & 1.4.2. Error management. \\
\hline & & 1.4.3. Airworthiness. \\
\hline & & 1.4.4. Homogeneity of the senses mobilized etc. \\
\hline & 1.5.Temporal adaptation of formats and & 1.5.1. Provide replacement versions. \\
\hline & contents & 1.5.2. Securitization. \\
\hline & & 1.5.3. Audio description. \\
\hline & & 1.5.4. Sign language. \\
\hline & & 1.5.5. Logical sequential order. \\
\hline & & 1.5.6. Distinction between levels of information. \\
\hline \multirow[t]{16}{*}{ Usability } & 2.1.Guidance & 2.1.1. Incentive. \\
\hline & & 2.1.2. Grouping or Distinction by the format. \\
\hline & & 2.1.3. Visual organization of the items. \\
\hline & & 2.1.4. Feedback Immediate. \\
\hline & & 2.1.5. Readability. \\
\hline & 2.2.Explicit control & 2.2.1. Explicit actions. \\
\hline & & 2.2.2. User control. \\
\hline & 2.3.Workload & 2.3.1. Brevity. \\
\hline & & 2.3.2. Information density. \\
\hline & & 2.3.3. Minimalism. \\
\hline & 2.4..Homogeneity / Consistency & 2.4.1. Homogeneity of codes. \\
\hline & & 2.4.2. Denominations. \\
\hline & & 2.4.3. Formats. \\
\hline & & 2.4.5. Procedures. \\
\hline & & 2.4.5. Labels. \\
\hline & & 2.4.6. Orders. \\
\hline
\end{tabular}


Table 1. Ergonomy Evaluation Proposed Model (continue)

\begin{tabular}{|c|c|c|}
\hline & Criteria & Subcriteria \\
\hline \multirow[t]{14}{*}{ Usability } & 2.5..Significance of Codes and & 2.5.1. Meaning. \\
\hline & Denominations & 2.5.2. Coherence of contents. \\
\hline & & 2.5.3. Biunivocity of commands and meanings. \\
\hline & 2.6.Error management & 2.6.1. Protection against errors. \\
\hline & & 2.6.2. Quality of the error messages. \\
\hline & & 2.6.3. Correction of errors. \\
\hline & 2.7.Compatibility & 2.7.1. Memory. \\
\hline & & 2.7.2. Perceptions. \\
\hline & & 2.7.3. Habits. \\
\hline & & 2.7.4. Skills. \\
\hline & & 2.7.5. Expectations. \\
\hline & & 2.7.6. User requirements. \\
\hline & 2.8.Adaptability & 2.8.1. Flexibility. \\
\hline & & 2.8.2. Taking into account the experience \\
\hline \multirow[t]{19}{*}{ Emotionality } & 3.1.Satisfaction & 3.1.1. Achievement of the goal. \\
\hline & & 3.1.2. Reached. \\
\hline & & 3.1.3. Measure of achievement. \\
\hline & 3.2.Degree of control & 3.2.1. Selection control. \\
\hline & & 3.2.2. Order of actions... \\
\hline & 3.3.Effort & 3.3.1. Perception of performance. \\
\hline & & 3.3.2. Procedures for maintaining the interaction. \\
\hline & 3.4.Challenge & 3.4.1. Need a challenge. \\
\hline & & 3.4.2. Need stimulation. \\
\hline & & 3.4.3. Self-realization \\
\hline & 3.5.Degree of independence & 3.5.1. Autonomy of the user. \\
\hline & & 3.5.2. Freedom of use. \\
\hline & 3.6. Cognitive interest & 3.6.1. Interest in the task. \\
\hline & & 3.6.2. Compatibility. \\
\hline & & 3.6.3. Fun of accomplishment of the task. \\
\hline & 3.7.Sensory interest & 3.7.1. Call for graphics, sounds, videos... \\
\hline & 3.8.Confidence & 3.8.1. Capability. \\
\hline & & 3.8.2. Perception of usability. \\
\hline & & 3.8.3. Perception of efficiency. \\
\hline \multirow{3}{*}{$\begin{array}{l}\text { Emotionality } \\
\text { (continue) }\end{array}$} & 3.9.Fancy & 3.9.1. Imagination. \\
\hline & & 3.9.2. Projection. \\
\hline & & 3.9.3. Imaginary context. \\
\hline \multirow[t]{23}{*}{ Persuasivity } & 4.1.Credibility & 4.1.1. Perceived reliability. \\
\hline & & 4.1.2. Expertise. \\
\hline & & 4.1.3. Loyalty. \\
\hline & & 4.1.4. Perceived legitimacy. \\
\hline & 4.2.Privacy policy & 4.2.1. Security feeling. \\
\hline & & 4.2.2. Perception of respect for rights. \\
\hline & & 4.2.3. Confidentiality. \\
\hline & 4.3.Solicitation & 4.3.1. Suggestion. \\
\hline & & 4.3.2. Teasing or setting in curiosity. \\
\hline & & 4.3.3. Priming actions. \\
\hline & 4.4.Personalization & 4.4.1. Perception of personalization. \\
\hline & & 4.4.2. Sense of belonging to a group. \\
\hline & 4.5.Initial accompaniment & 4.5.1. Piloting the first steps. \\
\hline & & 4.5.2. Encouragement. \\
\hline & & 4.5.3. Maintain the interaction. \\
\hline & 4.6.Attractiveness & 4.6.1. Emotional attraction. \\
\hline & & 4.6.2. Call to action. \\
\hline & & 4.6.3. Visual markup and orientation. \\
\hline & 4.7.Commitment & 4.7.1. Avoidance of disruptive external elements. \\
\hline & & 4.7.2. Increase in the psychological cost of the act. \\
\hline & 4.8.Hold & 4.8.1. Irrepressible and repetitive interactions. \\
\hline & & 4.8.2. Forms of release of the tension. \\
\hline & & 4.8.3. Consequences beyond the interaction with the media. \\
\hline
\end{tabular}

The first dimension represents the accessibility: The accessibility of a website is the fact of making it accessible to people who may have difficulties to consult it: the visually impaired, the elderly, the handicapped can be of physical, technological or structural origin [24]. Several relatively simple techniques are put in place by the W3C (Word Wide Web Consortium) [25]. According to Tim Berners-Lee, director of $\mathrm{W} 3 \mathrm{C}$ and inventor of the World Wide Web, Web Accessibility is: "Making the Web and its services available to all individuals, regardless of their hardware or software, their network infrastructure, their mother tongue, their culture, their geographical location, or their physical or mental abilities."[25]. To make web content more accessible, the World Wide Web Consortium (W3C) launched the Web 
Accessibility Initiative (WAI) in 1997. Among its activities, the WAI makes recommendations for content creators on the Web. These are called the Web Content Accessibility Guidelines (WCAG). These rules are intended for a variety of people.

The second dimension refers to the usability: it is defined by ISO 9241-11 as "the degree to which a product can be used, by identified users, to achieve defined goals effectively, efficiently and satisfactorily in a specified usage context. "[26]. Among the criteria known by this standard: efficiency, effectiveness, and satisfaction. The ergonomics expert Jakob Nielsen was one of the first to use the term usability, particularly in his book [27], and according to him usability is based on 5 criteria: Efficiency, Satisfaction, ease of use. Learning, ease of ownership, reliability.

The third one consists of emotional design and its criteria: As a result of the development of usability, various works [28], [29] have begun to emphasize the importance, not only of the dimensions of efficacy, efficiency and the satisfaction of the user placed in interaction with machines, but also the place of emotions related to this interaction. Jordan (1998) [4] was without a doubt one of the first to go beyond the notion of satisfaction, to apply that of pleasure to the relationship between the human and the products he uses. This pleasure (feeling of freedom, nostalgia, security, pride etc.) or the displeasure (feeling of aggression, frustration, embarrassment, anxiety etc.) provided by the interaction with a product are a predictor of use and purchase. In the same vein, Norman (2005) [30] distinguished three components in design:

1. Visceral design (which refers to aesthetics, pleasure related to the contemplation and use of an object),

2. Behavioral design (which refers to the usability of objects: ease of use, usefulness, etc.),

3. Reflexive design (which refers to the rationalization of a product, ie the technical and functional representation of a product. A product that a user builds based on past experiences).

The fourth dimension: in the same way as for accessibility, usability and emotionality, an appropriation of technological persuasion by ergonomics was attempted by the authors [31] who developed and validated a grid of ergonomic criteria intended to guide the inspection of persuasive interfaces. this dimension depicts the critera related to the interactive persuation: it is based on social, cognitive and emotional aspects that enrich the criterion approach of ergonomic inspection [27], [28]. Indeed, the technology becomes persuasive when the user lends qualities and properties that can increase the perceived credibility and therefore a sense of trust [6]. This involves surface elements of the interaction that reinforce information but also by the creation of a relationship that is built over time.

Therefore, we propose trough Figure 2 an iterative approach for the ergonomic assessment of information systems, it is based on two main steps: the evaluation and the improvement of the conception. The evaluation can be done according to the proposed hybrid model, following one of the three methodologies presented in the user centered evaluation methods section. The next section presents a case study that we have performed to evaluate our proposal.

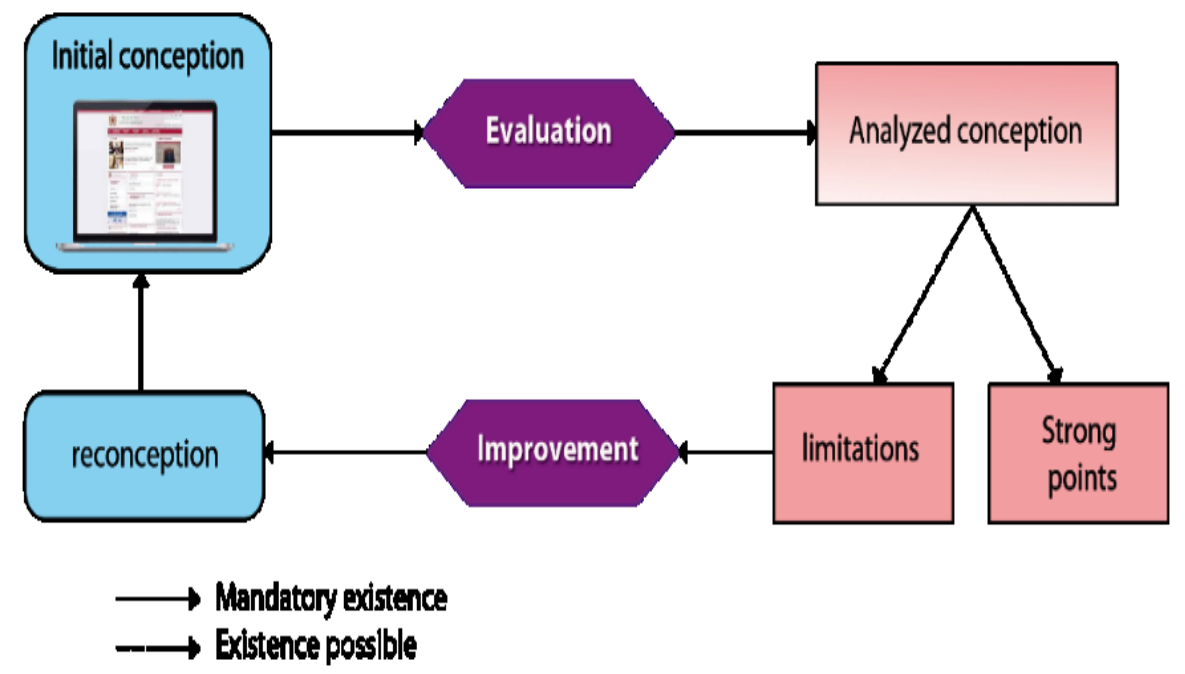

Figure 2. Iterative approach for the ergonomic assessment of IS 


\section{CASE OF STUDY}

\subsection{The information system SIMArech}

Based on the use of an effective application developed by a team of Abdelmalek Essaâdi University (UAE) dedicated to conduct collaborative extranet, this information system, called SIMArech, aims to support research administration by a unique technology solution in order to allow a streamlined and single point access to up-to-date information for researchers, research staff and administrative staff.

SIMArech is indeed the result of a collaborative way of working. This innovative best of breed solution has been designed to fulfill the needs of academic and research institutions: SIMArech is an IT platform that makes it easy to collect and manage data on research activities and outputs within an organization. Researchers, administrators and evaluators are given all the tools needed to monitor research results, enhance visibility and efficiently allocate available resources.

The modular nature of the system and the flexibility of its data model facilitate processing, organizing and transmitting information in accordance with international standards. At the same time, SIMArech provides the chance to easily shape local and national requirements [7]. We present trough Figure 3 the Overall interface of research projects:

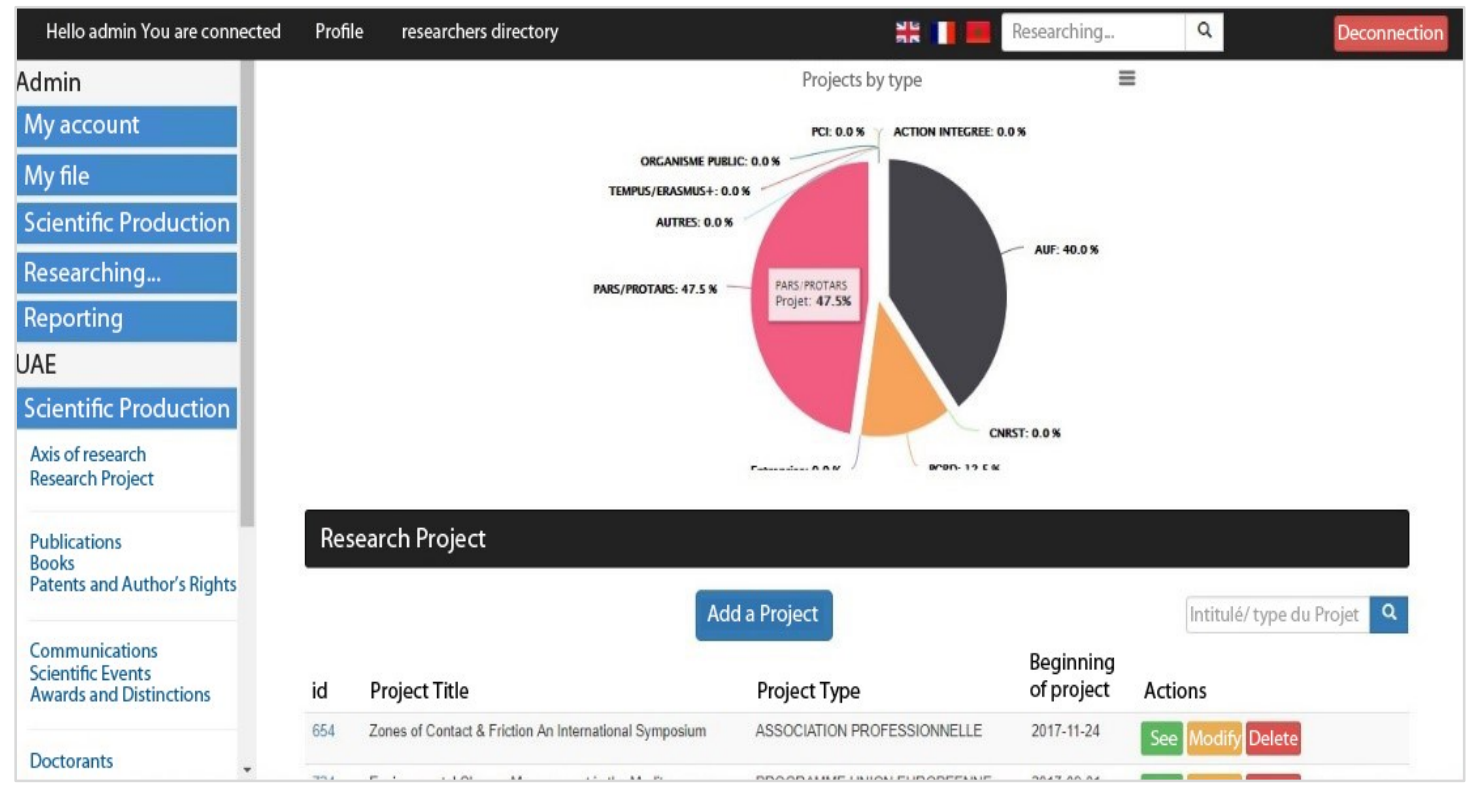

Figure 3. Overall interface of research projects [32]

\subsection{Ergonomic Evaluation of SIMARECH}

For the evaluation of SIMARECH, we have selected the expertise-based approach. Thus, an expert has participated in the evaluation step. The results of the evaluation are presented below.

\subsubsection{Strong points}

Figure 4 presents the result of accessibility evaluation of SIMARECH according to the criteria of perceptibility, usability, comprehensibility, robustness and temporal adaptation.

a. Perceptibility :The information is presented in a perceived way, for all types of users:

1. Colors: The limited number of colors (black, white blue gray). Different colors of luminance used allow their separation by color-blind people.

2. Texts and characters: Sans serif straight letters make it easy to read textual elements: Arial, Helvetica, Verdana. Serialized letters, with serif (Times New Roman) create a horizontal virtual line makes it easier to read long texts.

3. Organization of the general interface: Different accessibility for smartphones, tablets or touch screens, computers.

4. Online help: Online manual: detailed and detailed help for users (Static Help).

b. Temporal adaptation of formats and contents: Content and containers are distributed in different formats without loss of information (pdf, word, excel). 
c. Usability: The features are accessible, operational and applicable for all users.

d. Comprehensibility: Contents and containers appear logically, consistently and predictably.

e. Robustness: The contents and containers are robust and therefore easy to interpret correctly by users.

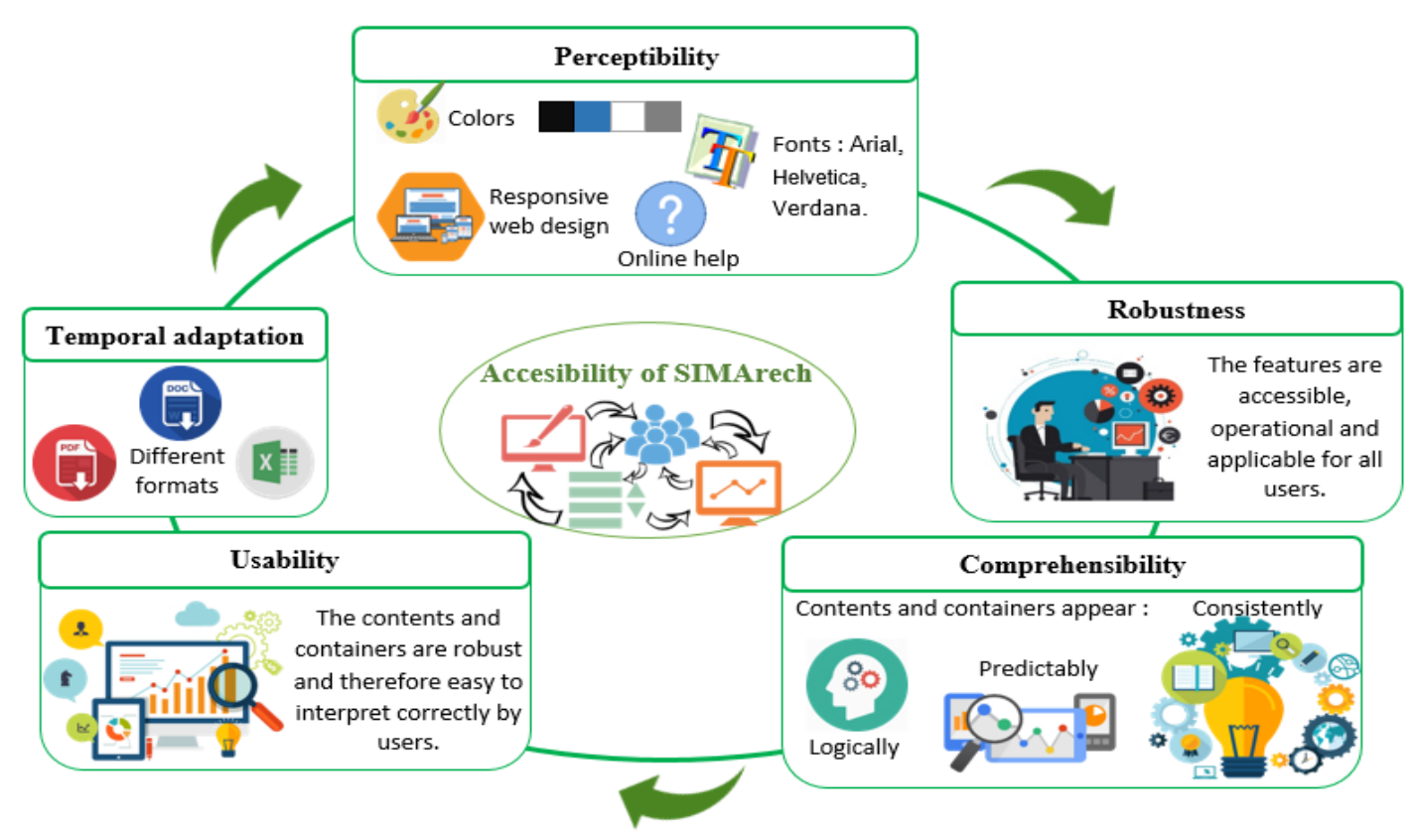

Figure 4. Accessibility evaluation of SIMARECH

Figure 5 presents the result of usability evaluation of SIMARECH according to the criteria of guidance, explicit control, adaptability, homogeneity and consistency, error management and compatibility

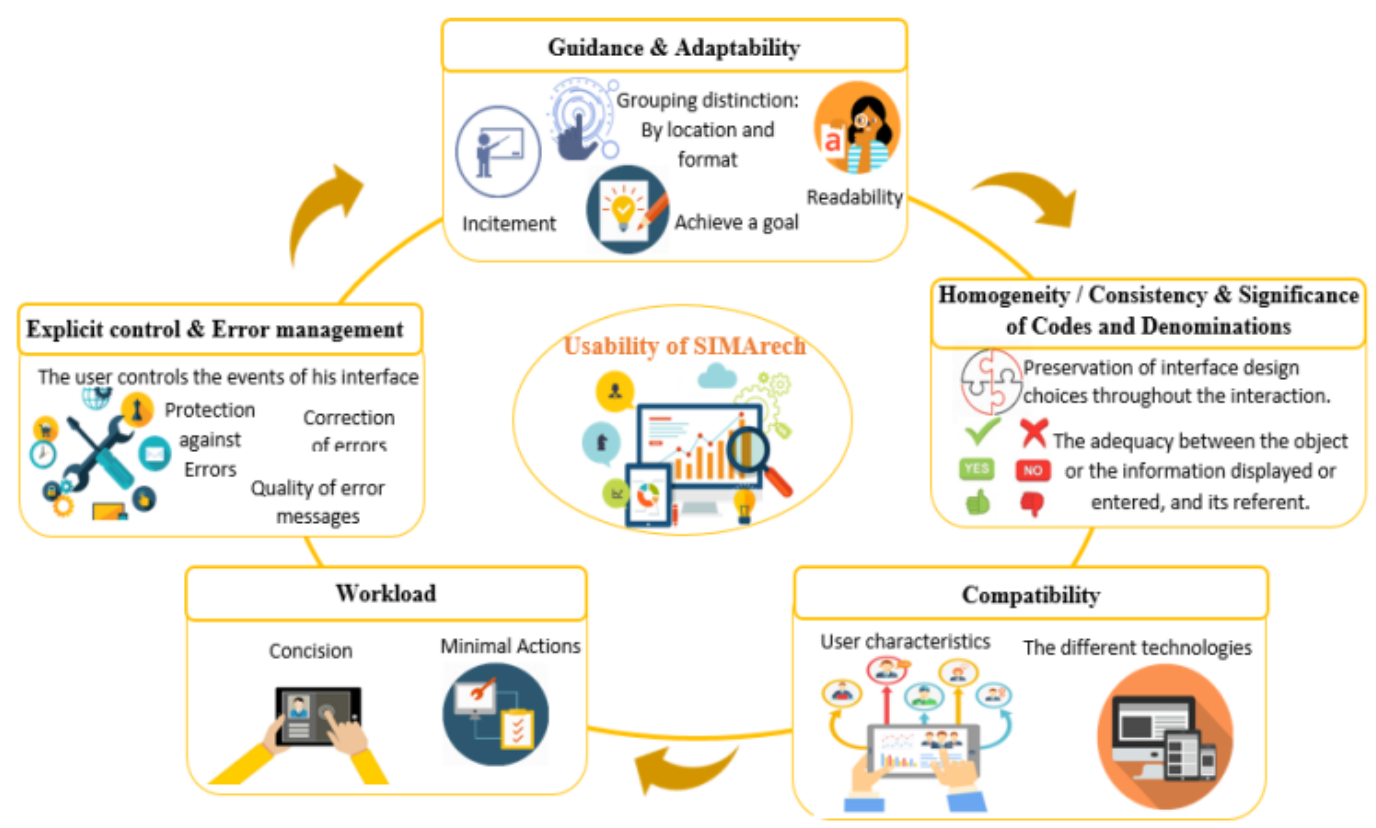

Figure 5. Usability evaluation of SIMARECH 
a. Guidance :

1. Incitement: There are all the incentive criteria that make it possible to judge the means implemented to let the user know the context in which he is and the actions he can perform. menu, the title of the page is identical to the active menu item)

2. Grouping distinction :

3. By location: geographically the elements are Remote and separate to distinguish and signify their difference (menu, titles, buttons, statistics, etc.).

4. By format: elements are distinguished by formats, colors, fonts and sizes.

5. Readability: Information is easily perceived and the size of the fonts, their format, the space between the lines, between the letters, the contrasts background / characters, etc. are well used.

6. Workload : brevity

7. Concision: The information is limited to reduce the effort provided by the user of reading. To present the information clearly and appropriately. There is no text that blinks or scrolls.

b. Explicit control: User inputs are explicitly defined by themselves and under their control, ambiguities and errors are limited.

c. Adaptability: Provide the user with different procedures, options, and commands to achieve a goal.

d. Error management :

1. Protection against Errors: set up means to detect and prevent errors, aims to prevent the user from making mistakes and, if this happens, he warns immediately (the form of an email address).

2. Quality of error messages, their relevance, their ease of reading, their precision as to the nature of the errors, indication of correction actions and Correction of errors: The means available to the user to correct their errors immediately. (The confirmation message of the deletion).

e. Homogeneity / Consistency: The IS provides users with a stable framework in the similar context in the system (Format and graphic design, menus, these points are stable in all interfaces).

f. Compatibility :The system is compatible with user characteristics:

1. The procedures required to complete task are compatible with the psychological characteristics of users;

2. Easy to use translations;

3. Transpositions, interpretations, or references to documentation are minimized;

4. Compatible with all browsers and their different versions and it is displayed correctly in all resolutions.

Figure 6 presents the result of emotional design evaluation of SIMARECH according to the criteria of degree of control and independence, challenge, confidence, sensory interest and satisfaction.

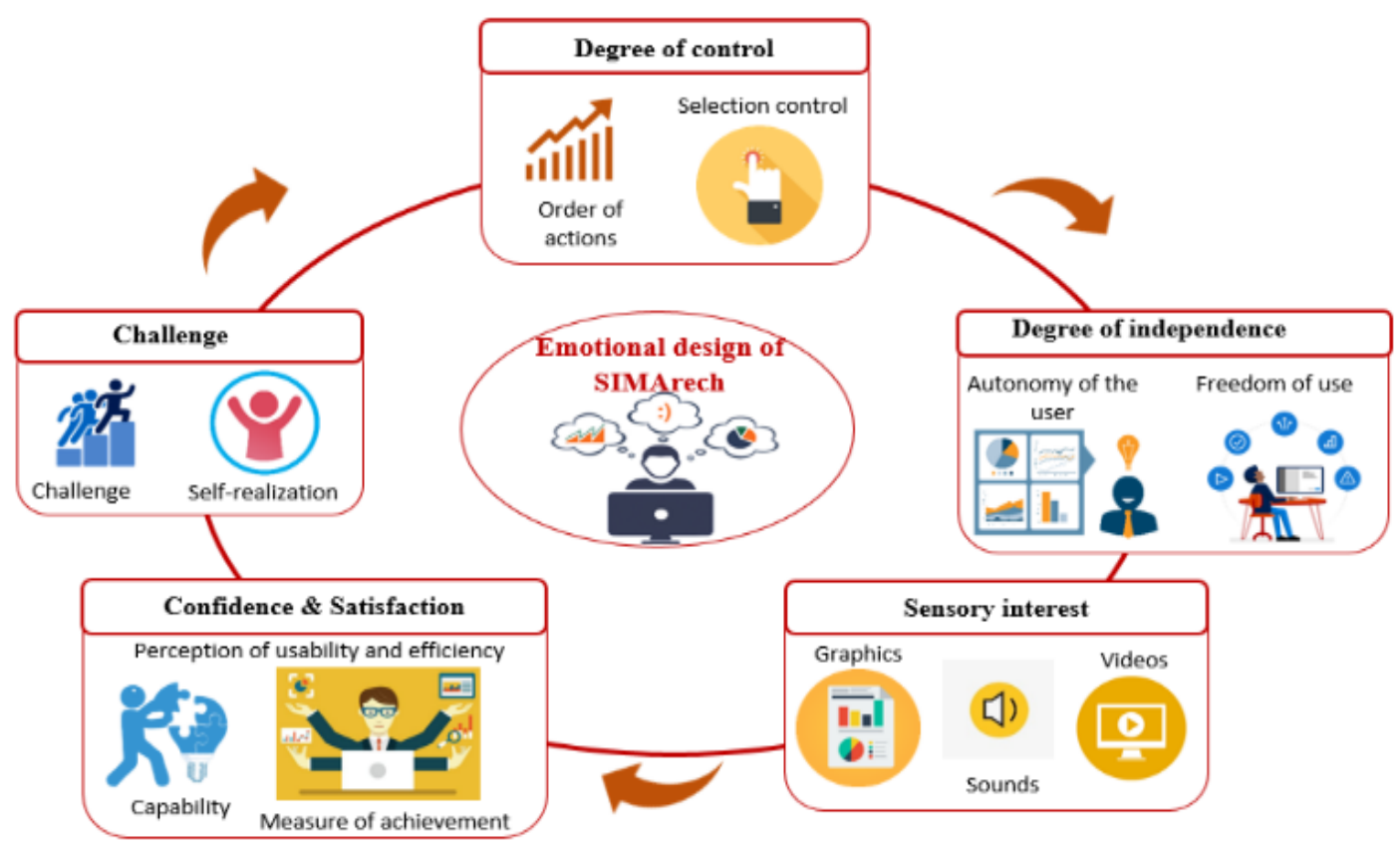

Figure 6. Emotional design evaluation of SIMARECH 
a. Degree of control : Selection control, Order of actions, etc

b. Challenge: challenge, Self-realization.

c. Degree of independence : The system guarantees the autonomy of the user to carry out activities

1. Updating and managing activities: creation, modification, deletion.

2. file insertion : photos

d. Confidence: Capability. Perception of usability. Perception of efficiency.

e. Sensory interest: Users get easily analyzed data and maximum information from graphs across multiple interfaces.

f. Satisfaction: Achieving the goal. Reached. Measure of achievement.

Figure 7 presents the result of interactive persuasion evaluation of SIMARECH according to the criteria of credibility, privacy, personalization, solicitation and commitment

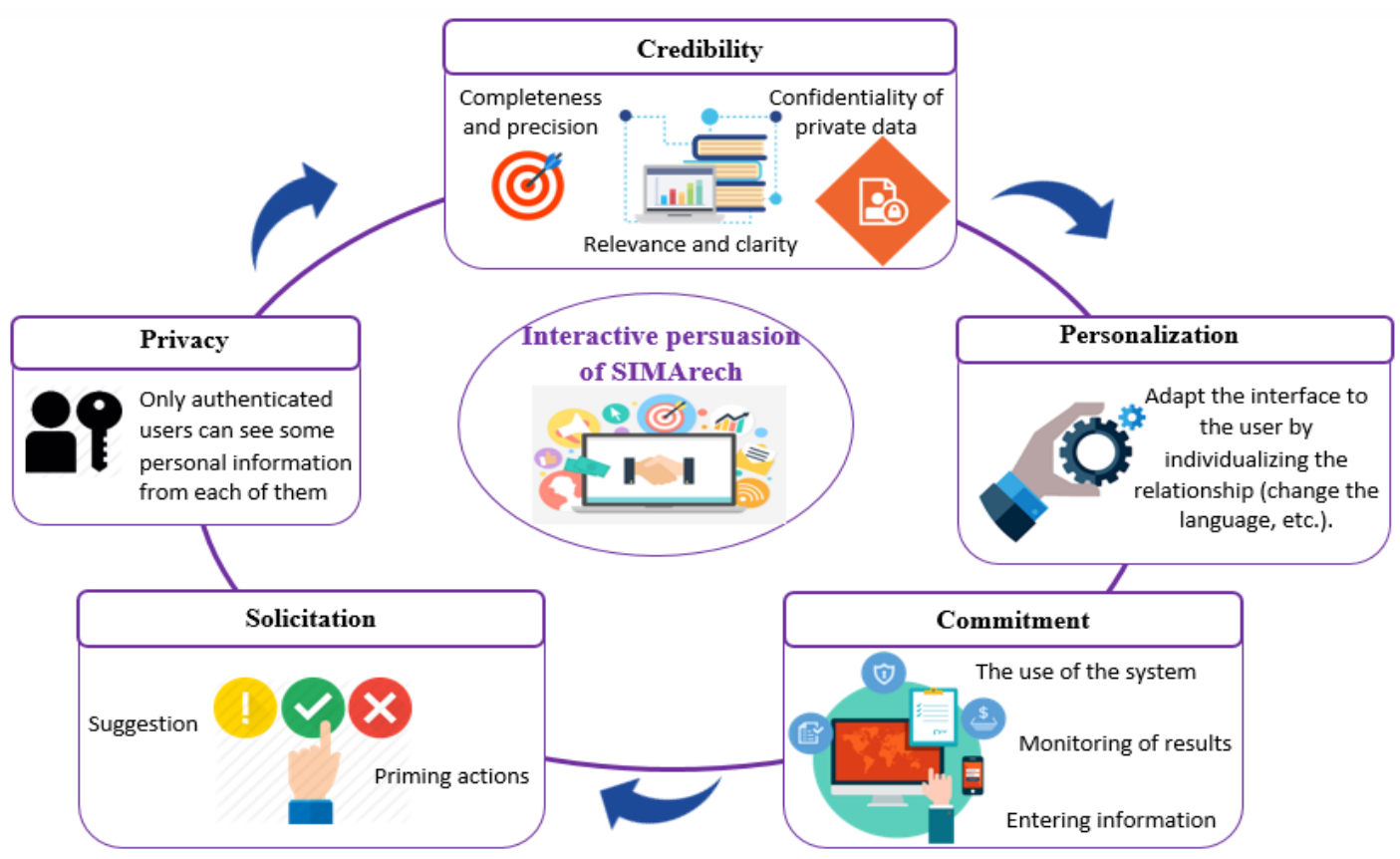

Figure 7. Interactive persuasion evaluation of SIMARECH

Static criteria

a. Credibility :

1. The factors related to the system:

2. Completeness and accuracy: The level of detail of the information given, for example the information sought in the system meets the expectations of users.

3. Relevance and clarity: the information is sufficiently clear so that "the information is easily identifiable". As well as the technical terms are explained so that the information is understandable by both experts and novice users.

4. Confidentiality of private data: users have control over the access and management of their personal data.

5. Third party factor: Testimonials from other users about the system: The system is certified by the Ministry of Higher Education, this certification is a real impact on trust remains largely dependent on credibility.

6. Individual factors: Familiarity with the system: past interactions with the old system version make it the most familiar. This user familiarity with the system predisposes to more confidence in using it.

b. Privacy: only the users of the system who can see the personal informations.

c. Personalization: A user has the ability to perform certain actions depending on his role, each role has a custom interface. 
Dynamic criteria

a. Solicitation: For the user to add, for example, a submission, he must go through validation steps (Suggestion.Basing actions).

b. Commitment :

1. Fidelity of users - direct visits or registration in the system (certified).

2. Quality of use - number of actions on the system, repeated visits, duration.

3. Registration - tel number, email, print, scientific output, etc.

4. Monitoring of results (statistics, dashboard, etc.).

\subsubsection{The Weaknesses of the Platform and Improvement Points}

Using this model we can deduce the weaknesses of the platform:

a. Most typing forms are very long and time consuming, there is no way to import data from different international base (articles, communications, etc.) instead of re-entering information into the platform.

b. Lack of compulsory signs for obligatory fields, which leads to wasting time during validation of a form.

c. There are difficulties in completing a few tasks quickly, and error messages sometimes do not help to solve problems or guide users which affects the execution time of a task or block them outright.

d. Lack of guidelines: sometimes there are mistakes to make some tasks in the platform.

e. Search processes sometimes fail (does not give accurate enough information).

f. The usable platform in English, French, Arabic. There is a lack of several languages like Spanish and German etc.

g. Lack of interactive spaces between users.

At this level the platform does not have sufficient orientations or means to ensure easy and errorfree interaction with the user [33]. Improvements could be made at certain levels:

a. Change the method of entering information: Integrate a Web of Science API that will automatically manage the database of journals in the system to be updated regularly and avoid blocking. Thanks to this API, the user can load the information of his publication into the SIMARECH platform to avoid manual entry.

b. Mark the required fields to enter data by a star.

c. Make the error messages presented by this system more orientative.

d. Customize search by adding filtering as an option to search in all search engines built into the platform.

e. Add other languages to the platform to offer personalized access to users by their preferable language, and to be well referenced in the various search engines of the targeted countries.

f. Add an interactive space (forums, chat, etc.) to encourage exchanges, communication, etc. between different users.

g. Thinking of doing distance training by discipline and actor of SIMARECH.

\section{RESULTS AND DISCUSSION}

Ensuring the proper use of an information system has always been a real concern for all organizations. The success of any web site depends on the satisfaction of the user and the users are only satisfied when they are able to do their work in a simple and efficient way [31], for this an ergonomic evaluation is essential.

however, there is currently no evaluation model combining the 4 dimensions: Accessibility, Usability, Emotionality, Persuasivity, Thus, in the ergonomic evaluation by a single criterion is not enough to properly define the strengths and weaknesses of an IS interface. Our contribution aims to provide a new model for the ergonomic evaluation of information systems that merges several criteria which will allow during the evaluation, not only to define the strong and weak points but also possible improvements for each criterion.

We used a methodological approach based on a scientific deductive methodology, which uses a logical sequence of research procedures to evaluate the design of the IS. This approach allows to define the strengths and deduce the limits while proposing improvements that can be taken during the redesign of an IS. In our case we applied this new model to a scientific research information system (SIMARECH), thanks to our proposed model we were able to discover the strengths and limitations of this system and to deduce improvements that could be made to some levels. 


\section{CONCLUSION}

The evaluation of interactive systems and more particularly of their human-machine interface has been a recurring problem for thirty years. The evolution of the means of interaction between the user and the machine as well as the needs and specificities inherent in the evolution of technology systematically requires new criteria and methods for the assessment of human-Machine interactions. In this context, this paper proposed an enhanced model for the ergonomic assessement of information systems that covers 4 dimensions: Accessibility, Usability, Emotionality, and Persuasivity. Further, it elucidated an iterative approach for the evaluation and the improvement of information systems ergonomy.

For the evaluation of our proposal, a situation of an information system for scientific research has been studied. For that aim, we have followed the expertise-based approach. Finally, we highlight the importance of calculating the relevance of the different specific criteria according to the application context. As a perspective, the proposed model can be used as an AHP (Analytical Hierarchy Process) [33] hierachy to calculate the weight of each criteria depending on the area of application and even the intended user profile.

\section{REFERENCES}

[1] S. Harper and Y. Yesilada, "Web Accessibility and Guidelines," Web Access., vol. 15, no. 1, pp. 61-78, 2008.

[2] S. Abou-Zahra, "Web Accessibility Evaluation," in Web Accessibility: A Foundation for Research, 2008, pp. $79-106$.

[3] J. Nielsen, "Heuristic Evaluation," in Usability inspection methods, 2011, pp. 25-62.

[4] P. W. Jordan, "Human factors for pleasure in product use," Appl. Ergon., vol. 29, no. 1, pp. 25-33, 1998.

[5] A. Némery and E. Brangier, "Set of Guidelines for Persuasive Interfaces: Organization and Validation of the Criteria," J. Usability Stud., vol. 9, no. 3, pp. 105-128, 2014.

[6] T. Wahyuningrum and K. Mustofa, "A Systematic Mapping Review of Software Quality Measurement: Research Trends, Model, and Method,” Int. J. Electr. Comput. Eng., vol. 7, no. 5, p. 2847, 2017.

[7] K. Benmoussa, S. Khoulji, M. Laaziri, and M. L. Kerkeb, "SIMARECH 3: A New Application for the Governance of Scientific Research," First Int. Conf. Affect. Comput. Mach. Learn. Intell. Syst. Sch., vol. 5, pp. 776-784, 2017.

[8] J. M. C. B. et A. TRICOT, "CHAPITRE 9: L'ÉVALUATION ERGONOMIQUE DES DOCUMENTS ÉLECTRONIQUES," 2008.

[9] J.-C. Sperandio, "L'ergonomie du travail mental (2e éd.) / Jean-Claude Sperandio,...," 1988.

[10] E. Brangier, M. Desmarais, N. Alexandra, and S. P. Tep, "Évolution de l'inspection heuristique: vers une intégration des critères d'accessibilité, de praticité, d'émotion et de persuasion dans l'évaluation ergonomique," 2015.

[11] J. M. Christian Bastien and D. L. Scapin, "Ergonomic Criteria for the Evaluation of Human-Computer Interfaces • Critères Ergonomiques pour l'Évaluation d'Interfaces Utilisateurs (version 2.1)," 1993.

[12] J. . Bastien, "Les Critères Ergonomiques: un pas vers une aide méthodologique à l'évaluation des systèmes interactifs. Thèse de doctorat, Université René Descartes (Paris 5), Paris.” 1996.

[13] B. Senach, "Evaluation ergonomique des interfaces homme-machine : une revue de la littérature," Chem. ..., no. March, p. 82, 1990

[14] S. Balbo, "Évaluation ergonomique des interfaces utilisateur : un pas vers l'automatisation," IMAG. p. $206,1994$.

[15] C. Farenc, "ERGOVAL: une méthode de structuration des règles ergonomiques permettant l'évaluation automatique d'interfaces graphiques," Thèse de Doctorat de l'Université Toulouse, 1997.

[16] J. M. C. Bastien and D. L. Scapin, "Evaluation des systèmes d'information et critères ergonomiques," Environ. évolués évaluation l'IHM, vol. 2, pp. 53-80, 2001.

[17] J. Huart and C. Kolski, L'évaluation de documents multimédias , Etat de l'art, no. January. 2008.

[18] A. WHITEFIELD, F. WILSON, and J. DOWELL, "A framework for human factors evaluation," Behav. Inf. Technol., vol. 10, no. 1, pp. 65-79, 1991.

[19] "ISO/TR 16982:2002 - Ergonomics of human-system interaction -- Usability methods supporting human-centred design.” [Online]. Available: https://www.iso.org/standard/31176.html. [Accessed: 04-Jul-2018].

[20] J. Nielsen, Usability Engineering, vol. 44, no. 3. 1993.

[21] T. Khodadadi, A. K. M. M. Islam, S. Baharun, and S. Komaki, "Evaluation of recognition-based graphical password schemes in terms of usability and security attributes," Int. J. Electr. Comput. Eng., vol. 6, no. 6, pp. 2939-2948, 2016.

[22] K. C. Grislin M., "Evaluation des interfaces homme-machine lors du développement de système interactif," Tech. Sci. Informatiques, vol. 3, pp. 265-296, 1996.

[23] A. Trabelsi, "Contribution à 1 ' évaluation des systèmes interactifs orientés agents To cite this version :," 2009.

[24] K. Surendro and Olivia, "Academic Cloud ERP quality assessment model," Int. J. Electr. Comput. Eng., vol. 6, no. 3, pp. 1038-1047, 2016.

[25] P. T. Berners-lee, "Qu'est-ce que «l'accessibilité » d'un site Internet? Le référentiel en matière d'accessibilité," 2008.

[26] ISO, "ISO 9241-11," Ergonomic requirements for office work with visual display terminals (VDTs) -- Part 11: Guidance on usability, 1998.[Online]. Available: http://www.iso.org/iso/catalogue_detail.htm?csnumber=16883.

[27] J. Nielsen, Usability engineering. Academic Press, 1993.

[28] J. Nielsen and R. L. Mack, "Heuristic evaluation," in Usability Inspection Methods, 1994, pp. $25-62$. 
[29] E. Brangier and J. Barcenilla, "Concevoir un Produit Facile à Utiliser," in Concevoir un produit facile à utiliser, 2003.

[30] D. A. Norman, Emotional Design - Why we love (or hate) everyday things, no. 1. 2004.

[31] E. Brangier, N. Alexandra, and S. Séverine, "Experimental validation of persuasive criteria for CHI : interfaces," 2015.

[32] “SIMARech 3.” [Online]. Available: http://simarech.uae.ac.ma/. [Accessed: 01-Feb-2018].

[33] A. Nayebpour and H. Rashidi, "Presenting Metrics for Evaluation of Expert Systems Based on Service-Oriented Architecture," Int. J. Electr. Comput. Eng., vol. 3, no. 5, pp. 688-695, 2013. 